\title{
Effects of process parameters on friction self-piercing riveting of dissimilar materials
}

\author{
Xun Liu', Yong Chae $\mathrm{Lim}^{2}$, Yongbing $\mathrm{Li}^{3}$, Wei Tang ${ }^{2}$, Yunwu $\mathrm{Ma}^{3}$, Zhili Feng ${ }^{2}$, Jun $\mathrm{Ni}^{1}$ \\ 1. Department of Mechanical Engineering, University of Michigan, Ann Arbor \\ 2. Materials Science and Technology Division, Oak Ridge National Laboratory \\ 3. School of Mechanical Engineering, Shanghai Jiao Tong University
}

\begin{abstract}
In the present work, a recently developed solid state joining technique, Friction self-piercing riveting (FSPR), has been applied for joining high strength aluminum alloy AA7075-T6 to magnesium alloy AZ31B. The process was performed on a specially designed machine where the spindle can achieve the motion of sudden stop. Effects of rivet rotating rate and punch speed on axial plunge force, torque, joint microstructure and quality have been analyzed systematically. During F-SPR, higher rotating rate and slower punch speed can reduce axial force and torque, which correspondingly results in a slightly smaller interlock between rivet leg and joined materials. Improved local flowability of both aluminum and magnesium alloys under a higher rotating speed results in a thicker aluminum layer surrounding the rivet leg, where formation of Al-Mg intermetallics was observed. Equivalent joint strength obtained in this study are higher than the yield strength of the AZ31 Mg alloy. One of the tensile failure modes is the rivet fracture, which is due to local softening of rivet leg from frictional heat. Other two failure modes include rivet pullout and shear through of bottom sheet.
\end{abstract}

\section{Keywords}

Friction self-piercing riveting, dissimilar materials, process parameters

\section{Introduction}

Lightweight vehicles are receiving growing attention in recent years for energy and environmental concerns. High specific strength materials, including ultra-high strength steel, aluminum and magnesium alloys are gradually applied into vehicle bodies, which raises the demand of multi-material vehicle structures. Accordingly, development of reliable and economical dissimilar material joining process is required. Considering the incompatible physical properties of different materials and formation of brittle intermetallic compounds, extensive researches on solid state welding and mechanical joining techniques have been conducted and showed superiorities over traditional fusion welding process. Friction stir welding (FSW) is a promising solid state process for welding dissimilar materials. Somasekharan and Murr (2004) employed this technique to join aluminum alloy 6061 to magnesium alloy and the weld zone shows an intercalated microstructure with recrystallized shear bands rich in either $\mathrm{Mg}$ or $\mathrm{Al}$ element. Liu et al. (2014) investigated FSW of aluminum alloy to advanced high strength steel and the highest joint strength could reach $85 \%$ of the base aluminum alloy. Besides solid state welding, there are several newly 
developed mechanical joining techniques. Gao et al. (2009) developed the friction stir blind riveting process, which improves traditional riveting by rotating the rivet while penetrating it into the workpiece. This eliminates the requirement of pre-drilled holes. Robustness of the process is shown under a wide range of operating parameters and a higher static and fatigue strength can be obtained compared with that obtained from resistance spot welding. Li et al. (2015) further studied the process with an optimized blind rivet geometry, especially at the rivet tip, which is machined to a sharp profile and can penetrate the workpiece with a cutting action. This significantly reduces the riveting force. Another mechanical joining process is the flow drill screwdriving process, which was first developed by Skovron et al. (2014). The technique combines friction hole drilling, thread forming and screw fastening into one single process and reduces weld cycle time to a large extent. During the process, a rotating screw is driven to pierce and extrude the material with the assistance of friction heating. Threads are formed in this created extrusion. The two workpiece sheets can finally be securely clamped together by screwdriving of the fastener into these formed threads. Skovron et al. (2015) also investigated the effects of workpiece temperature on this joining process. A reduced process time and installation torque for the final fastening of screw can be observed by preheating the workpiece to a higher temperature. The third innovative mechanical joining process is called friction bit joining, which was first developed by Miles et al. (2010). During the process, the joining bit first cuts through top workpiece sheet. The bit and surrounding material are heated by friction and finally the bit is left on the workpiece as a filler material. Squires et al. (2015) applied this process to spot weld aluminum alloy 7075-T6 with dual phase 980 steel and achieved good joint quality. Lim et al. (2015) further combined adhesive bonding with this process for joining $\mathrm{Al}$ alloy to advanced high strength steel DP980. The corrosion behavior was studied and the assistive adhesive bonding was shown to mitigate the corrosion impact.

Self-piercing riveting (SPR) is also one of the promising mechanical joining technologies for dissimilar materials in addition to the abovementioned processes. During SPR, a semi-tubular rivet is punched through upper sheets of the stacked workpiece and flares into the bottom sheet based on the geometry of the supporting die. Outward flaring of the rivet leg generates mechanical interlock between workpiece and the joint quality depends on the interlock distance and remaining material thickness of the bottom sheet. Compared with traditional riveting process, no predrilled hole is required and corresponding workpiece alignment is not critical. He et al. (2008) reviewed joining mechanics, weld quality and different types of defects related to SPR process. Abe et al. (2006) investigated the feasibility of SPR for joining aluminum alloy to mild steel through both experiments and finite element models. It is shown that the processing window is larger by placing steel on top of aluminum than the reverse configuration. Weld defects are categorized into lower sheet penetration, lower sheet necking and the separation of sheets. Mori et al. (2014) studied the feasibility of SPR for joining multiple layers of steel to aluminum sheet. Han and Chrysanthou (2008) evaluated the surface coating effect on SPR of high strength low alloy steel to aluminum. Li et al. (2013) did SPR for joining aluminum alloy 6061 to magnesium alloy AZ31B. Di Franco et al. (2010) demonstrated that SPR can effectively join carbon fiber composite to aluminum alloys blanks from both experimental and numerical analysis. Mandel and Krüger (2012) further studied the corrosion issues for SPR joints between carbon fiber reinforced polymer (CFRP) and aluminum alloys. Despite these studies, applications of SPR are limited when applied to ultra-high strength steels or low ductility materials, such as magnesium alloys and high strength aluminum (7xxx series). High strength materials are difficult to be pierced through and the rivet leg can get bulged before it enters into the lower sheet, as reported by Mori et al. (2006) when they applied SPR for joining ultra-high strength steel to aluminum alloy. Furthermore, large punching force is generally required and die wear is accelerated. For materials with limited formability, fracture and cracks are likely to occur due to the localized extensive 
plastic deformation, especially on the bottom sheet, as reported by Durandet et al. (2010) when they studied SPR of magnesium alloys.

In order for improvement on the SPR process, one approach is to optimize the rivet and die geometry as well as the relative configuration of workpiece, as was conducted by Mori et al. (2006). Another approach is to adapt this original cold forming process into a coupled thermal-mechanical process. Wang et al. (2011) investigated the effects of different preheating temperature on SPR of wrought AZ31 Mg alloy. According to Jäger et al. (2004), a higher temperature can activate additional slip systems in the HCP crystal structure of $\mathrm{Mg}$, which helps improve plasticity and eliminate cracking in the bottom sheet. Moreover, a larger rivet interlocking was also observed. In addition to preheating, external heating source has been introduced for development of a hybrid SPR process. Durandet et al. (2010) applied laser to the bottom Magnesium sheet and reported dynamic recrystallization to be another possible factor for suppressing crack generation and joint discrepancies. Troitskii (1969) reported the electro-plastic softening effect. Based on this phenomenon, Lou et al. (2013) implemented a high density electrical current during SPR of Al 6061 to DP780 advanced high strength steel. Punching force can be reduced during the process. In configurations of aluminum on the top, the electrical current helps increase interlocking and result in a higher tensile joint strength. When steel is placed on the top, the steel can be pierced through at an earlier stage under electrically assisted conditions.

Li et al. (2013) proposed the friction self-piercing rivet (F-SPR) process, during which the rivet is rotating while being punched into the workpiece. The additional heat is therefore generated from local friction. The F-SPR process integrates traditional SPR machine with auxiliary heating sources into one single equipment, and thus can greatly improve process cycle time. Effects of spindle speed and feed rate on the elimination of cracks inside and on the bottom of the joint were investigated and a two stage F-SPR process was proposed to obtain the optimized joint quality. They showed the F-SPR joint tensile shear strength $(\sim 4 \mathrm{kN})$ is twice as much as that of a SPR joint $(\sim 2 \mathrm{kN})$. Ma et al. (2016) established a coupled thermomechanical finite element model to study the transient formation of the F-SPR joint. The temperature distribution inside the joint was found to be in accordance with the effective plastic strain distribution. Ma et al. (2015) further optimized the F-SPR rivet from commercial SPR rivet in terms of hardness and geometrical features. However, considerable amount of cracks were observed in those FSPR joints obtained from their works, which may be caused by slow reduction of rotating speed at the end of joining process.

In this study, the F-SPR process is investigated on a specially designed machine manufactured by the MegaStir Company where the high-speed rotating spindle can achieve a sudden stop motion within $0.3 \mathrm{~s}$. This helps avoid residual spinning of the rivet as the punch starts to retract from workpiece. High strength aluminum alloy AA7075 and magnesium alloy AZ31B are joined. Effects of process parameters, such as rivet rotational speed and punch speed, are analyzed and correlated to the obtained punching force and torque during the joining process, which are then further related to microstructure and corresponding mechanical joint qualities.

\section{Experimental details}

\subsection{Materials and experimental setup}


Thickness and mechanical properties of the high strength aluminum alloy AA7075-T6 and magnesium alloy AZ31B are listed in Table 1. DZ series die, which is designed referring to the criteria of the traditional SPR process, has been employed and detailed dimensions of the die and rivet geometry are given in Fig. 1. The rivets are made of mild steel with no heat treatment nor coating and the hardness in the rivet leg region is around HV 260 before the welding process. A torx shaped hole is designed on top of the rivet to transmit rotation motion of the spindle. One of the critical parameters for SPR process is the plunge depth, which is defined as the travel distance after the rivet tip touches the top surface of higher workpiece. Based on the length of rivet leg and several preliminary tests, plunge depth was selected at $5.84 \mathrm{~mm}$ for all the experiments conducted in this study. Pre-clamping force on the workpiece was controlled in each weld with a torque wrench. $\mathrm{Al}$ is placed on top of $\mathrm{Mg}$ sheet as the primary configurations, where two levels of rotating speed, $2000 \mathrm{rpm}$ and $3000 \mathrm{rpm}$, and two levels of punching speed, $1.82 \mathrm{~mm} / \mathrm{s}$ and $2.75 \mathrm{~mm} / \mathrm{s}$, are investigated. As a comparison, welds have also been performed with aluminum sheet placed at bottom in a specific processing condition of $3000 \mathrm{rpm}$ and $2.75 \mathrm{~mm} / \mathrm{s}$.

Table 1 Mechanical properties and sheet thickness of AA7075-T6 Al alloy and AZ31B-O Mg alloy

\begin{tabular}{lllll}
\hline Material & Yield strength & Uniaxial tensile strength & Elongation & Thickness \\
\hline AA7075-T6 & $503 \mathrm{MPa}$ & $572 \mathrm{MPa}$ & $11 \%$ & $1.6 \mathrm{~mm}$ \\
\hline AZ31B-O & $169 \mathrm{MPa}$ & $297 \mathrm{MPa}$ & $8 \%$ & $2.3 \mathrm{~mm}$ \\
\hline
\end{tabular}
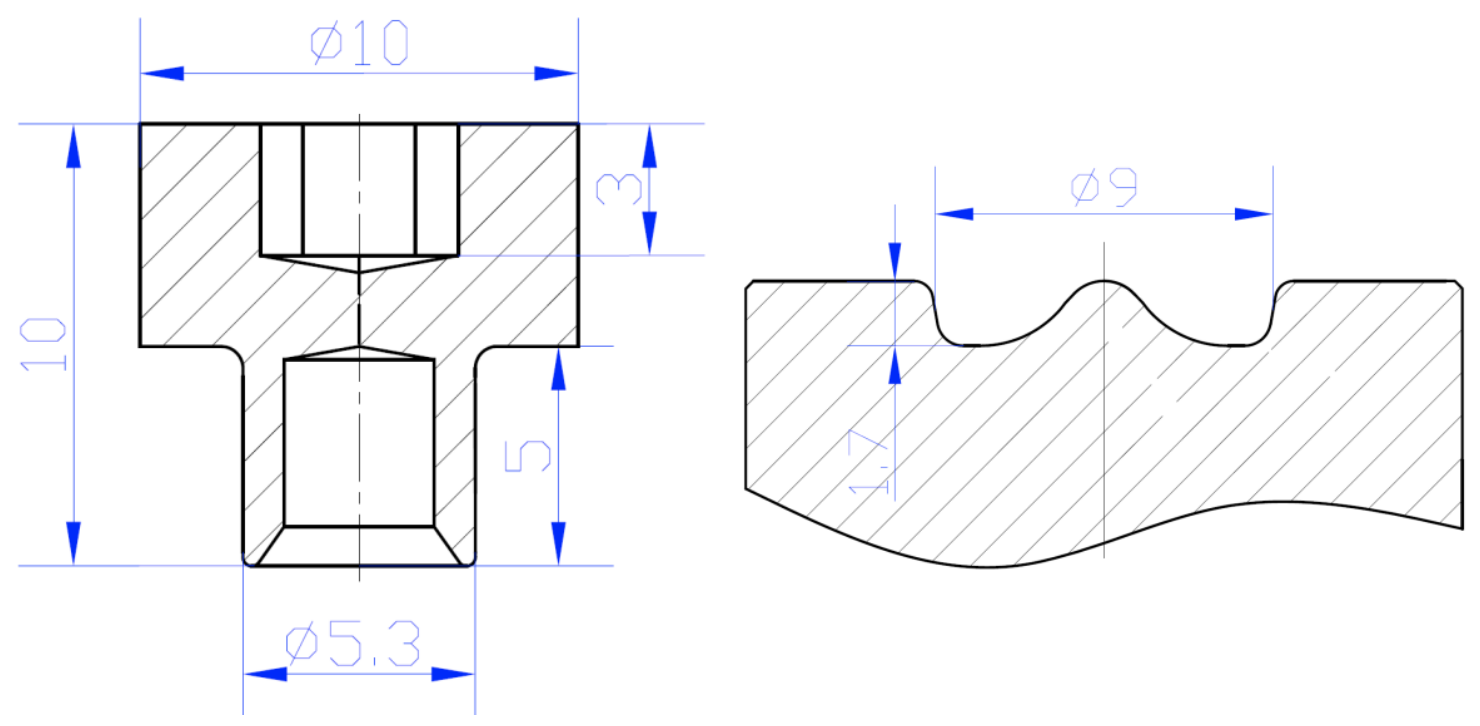

Figure 1 Detailed rivet and die geometry (Unit: $\mathrm{mm}$ )

\subsection{Joint quality characterization}

For each welding condition, two welds were repeated for cross section analysis and additional three welds were repeated for joint strength evaluation. Joints were sectioned in the rivet center and prepared following standard grinding and polishing procedures for optical (Nikon Epiphot) and field emission scanning electron microscopic (FE-SEM, Hitachi S4800) analysis. Elemental mapping was measured by the X-Ray energy dispersive spectroscope (EDS) attached to the SEM machine. Also, microhardness tester (Leco LM 100AT) was used to measure Vickers microhardness of the base metals and rivet legs. 
The measurement condition was: $200 \mathrm{~g}$ of load, 13 seconds of dwell time and $250 \mu \mathrm{m}$ spacing on rivet leg. Fig. 2 shows the geometry of the tensile shear specimen. During tensile tests, shims with appropriate thickness were inserted in between grips of the MTS tensile machine and tensile specimen to avoid undesirable bending effects. The tensile test is performed at a rate of $10 \mathrm{~mm} / \mathrm{min}$. Since the length of the overlapping area is $25 \mathrm{~mm}$, the equivalent strain rate can be determined to be around $0.0067 / \mathrm{s}$.
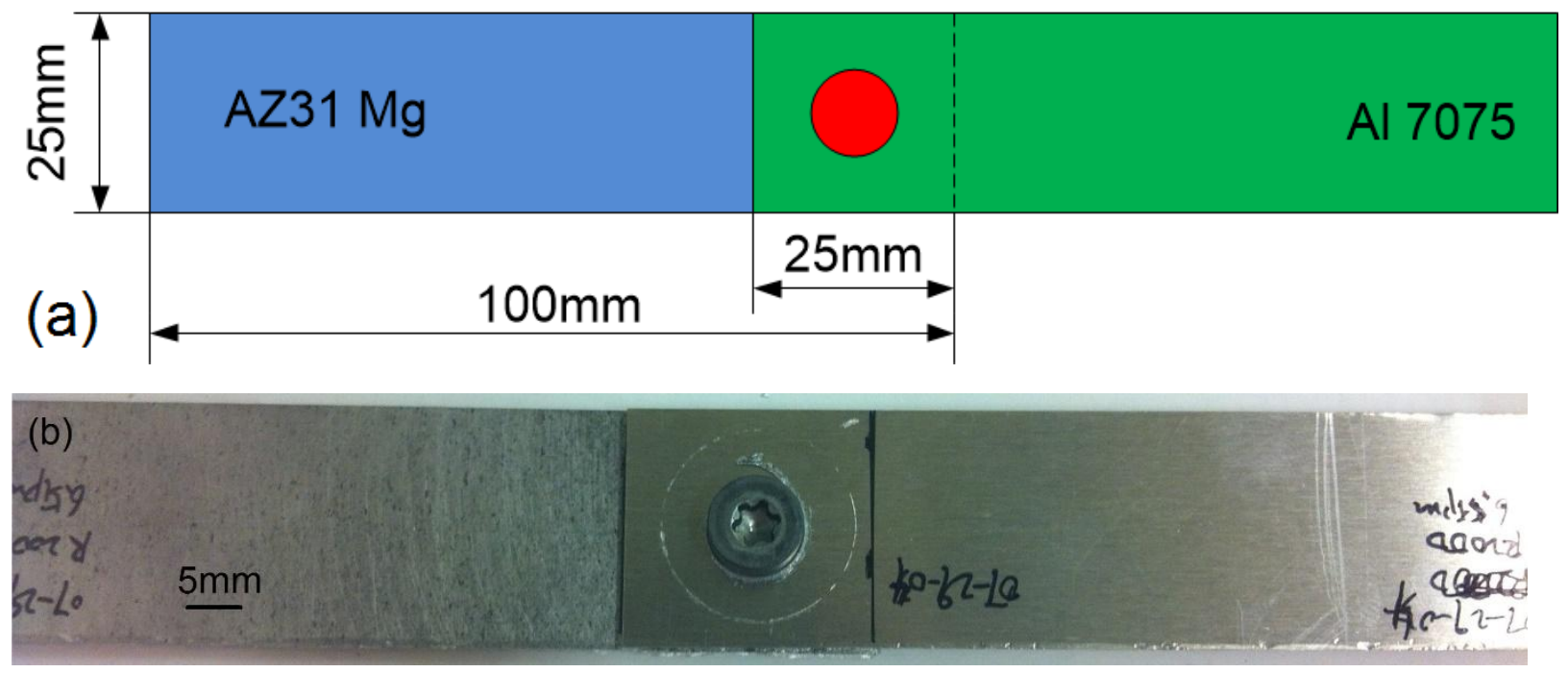

Figure 2 Tensile shear specimen geometry: (a) Schematic illustration; (b) Actual joint

\section{Results and discussion}

\subsection{Punch force and torque comparison in conditions of $\mathrm{Mg}$ on the bottom}

Fig. 3 shows the relationship of punching force with regard to the tool depth under the four processing conditions where $\mathrm{Mg}$ sheets were placed on the bottom. Here the reference frame for tool depth is the same as that for plunge depth. Zero tool depth is when the rivet tip touches the top surface of higher workpiece. As the rivet moves further down, the tool depth increases until it reaches the desired plunge depth. Only two curves out of the total 5 tests are presented for each condition. Compared with traditional self-piercing riveting, where the punch axial load is generally in the order of $10-100 \mathrm{kN}$ as reported by Porcaro et al. (2006), F-SPR required a much smaller peak load (less than $10 \mathrm{kN}$ ). This can be explained from both a slower plunging speed and the thermal softening of material due to localized frictional heating. Punching speed of traditional SPR process is generally much faster. For example, a speed of $2.5 \mathrm{~m} / \mathrm{s}$ was employed by Abe et al. (2006). As the rivet started to touch and plunge into the top aluminum sheet, the axial load increases. In conditions of slower punch speed, the axial force first reached a small peak at position of around $1 \mathrm{~mm}$ depth. Regarding conditions of faster punch speed, the first peak was reached at approximate $1.2 \mathrm{~mm}$ depth. It should be noticed that these two values are less than the thickness of AA7075-T6 workpiece, which is 1.6mm. Besides, according to Haque et al. (2012), both of the work pieces will be bent downward into the die cavity as rivet is being driven into the upper sheet, which accordingly allows a longer punch stroke before the top sheet is penetrated. From the force curve, it can 
be observed that the axial force already started to decrease before the $1.6 \mathrm{~mm}$ tool depth. Similar phenomenon was also observed in the plunge stage of friction stir welding process, as reported by Park (2009), where a temporarily intermediate axial force drop occurs before the final tool shoulder abrades against workpiece top surface. This has generally been considered from the aspect that as the tool pin is gradually inserted into workpiece, the amount of heat generated by friction and plastic deformation would increase to an overshoot level where material deformation resistance can be reduced to a larger degree. Consequently, the required force for pushing the pin further downward is reduced. Based on the similar mechanism, the frictional heating during F-SPR process can reduce the punch load before the rivet pierces through the top workpiece. After that, the rivet leg starts to plunge into the bottom $\mathrm{Mg}$ sheet, which has a lower plastic flow stress compared with AA7075-T6. The punch load remained at a relatively small value until the bottom surface of $\mathrm{Mg}$ was in full contact with the die and the rivet leg started to flare out. The punch load then increased with a much higher slope and reached the peak as the rivet head penetrated into the top AA7075-T6 at the desired plunge depth.
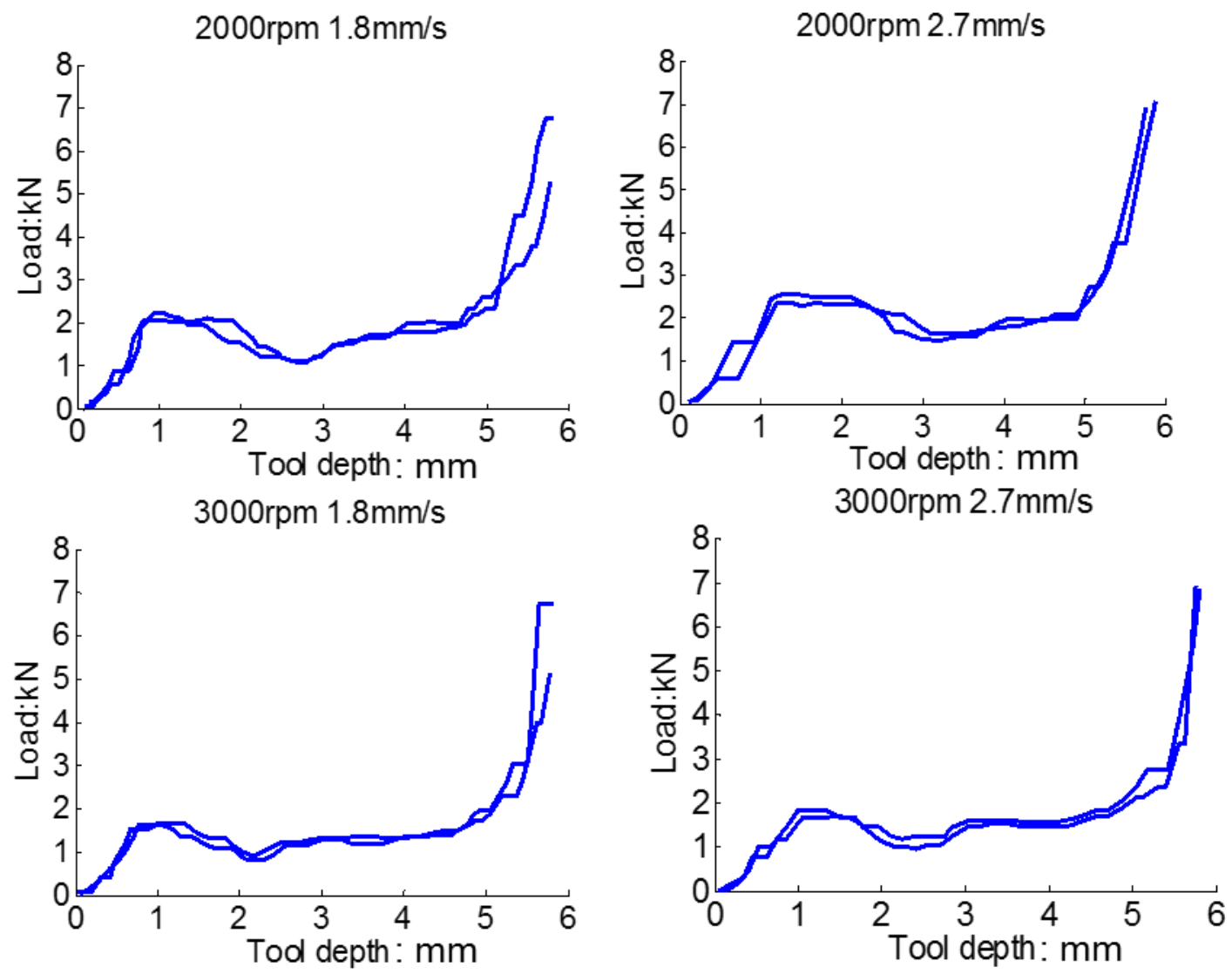

Figure 3 Relationship of axial punching load with regard to tool depth under different process conditions

Regarding the first peak load under different process conditions, a slower punch speed and higher rotating speed can lower its value. Increasing rotating speed and punching speed with the same ratio at conditions tested in this study still results in a smaller axial load indicates that the rotating speed is a more dominant factor, which is very likely to be due to its direct effect on frictional heat generation rate. On the other hand, under a higher plunging speed the force continued rising for a longer distance before it started decreasing. This can be explained as that for the same heat generation rate, faster plunging speed needs 
longer distance to accumulate same amount of frictional heat, which helps soften the material and reduce the axial force to punch the rivet further into workpiece.

Effects of process parameters on the final peak force are shown in Fig. 4. The final punching load consists of two components, one is the rivet head compressed against top aluminum surface and the second is the inserted rivet and stacked workpiece compressed against bottom die. Similar to the first peak of the force curve, this final punching force is smaller under conditions of higher rotating speed or slower plunge speed. Both can be explained from the aspect of thermal softening effect. Higher rotating speed elevates the frictional heat generation rate and slower plunge speed allows longer time period to accumulate heat. Accordingly, smaller axial force is required to push the rivet to the same final position.

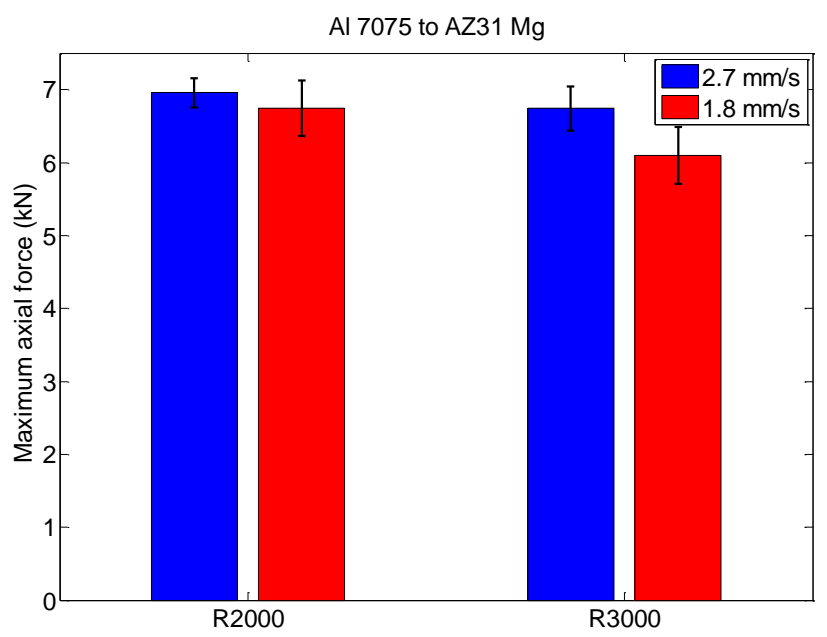

Figure 4 Comparison of the peak axial force under different process parameters

Fig. 5 shows the relationship of spindle torque as a function of plunge depth under various process conditions. Similarly, only two curves from the total 5 tests are plotted in each condition. It can be noticed that the value started at around $1 \mathrm{Nm}$, which is related to the intrinsic driving torque for rotating the machine spindle. Similar to the punching load, it can be observed that the torque increased in the beginning and then started to decrease before the rivet pierced through the top sheet. Higher rotating speed also resulted in a smaller first peak. However, overall the increasing slope in the beginning was larger for torque compared with that for the punch force curve. Since torque is composed of frictional shear stress at the interface between rivet leg and workpiece, the input frictional heating rate can be approximated by the product of rotating speed and torque value. In conditions of higher rotating speed, even though torque is reduced, it can be noticed that the heat input rate is still higher, which softens the material to a larger degree and is consistent with axial force measurement result. After the rivet entered into $\mathrm{Mg}$ sheet, the torque remained at a relatively constant value, which was basically independent of rotating speed. On the other hand, overall the punch speed was an insensitive factor for the torque curve except at the final plunge depth, as compared in Fig. 6. The maximum torque is achieved when the rivet head bottom surface, including the area inside and outside of the tubular leg, starts to abrade against aluminum top surface. Since higher axial force leads to a larger normal pressure at this rivet/workpiece interface, which generally increases frictional force, influence of process parameter on the maximum axial force therefore follows the similar trend as that on the maximum torque. Besides, it can be noticed 
that the effect of punch speed is more significant under higher rotating speed. Since punching speed directly determines the length of joining cycle, the larger frictional heat generation rate from higher rotating speed would make this a more critical parameter.
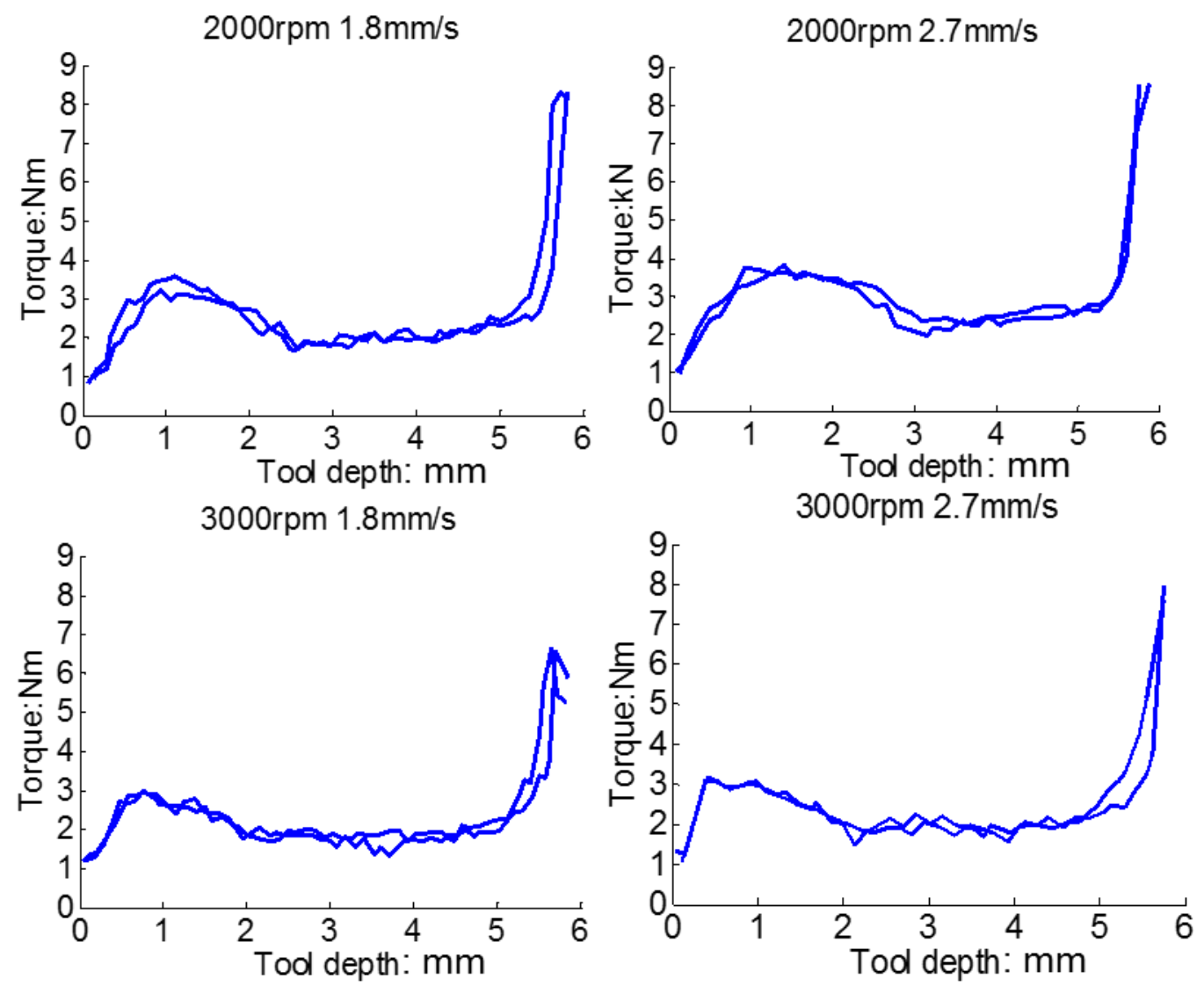

Fig. 5 Relationship of spindle torque with regard to tool depth under different process conditions

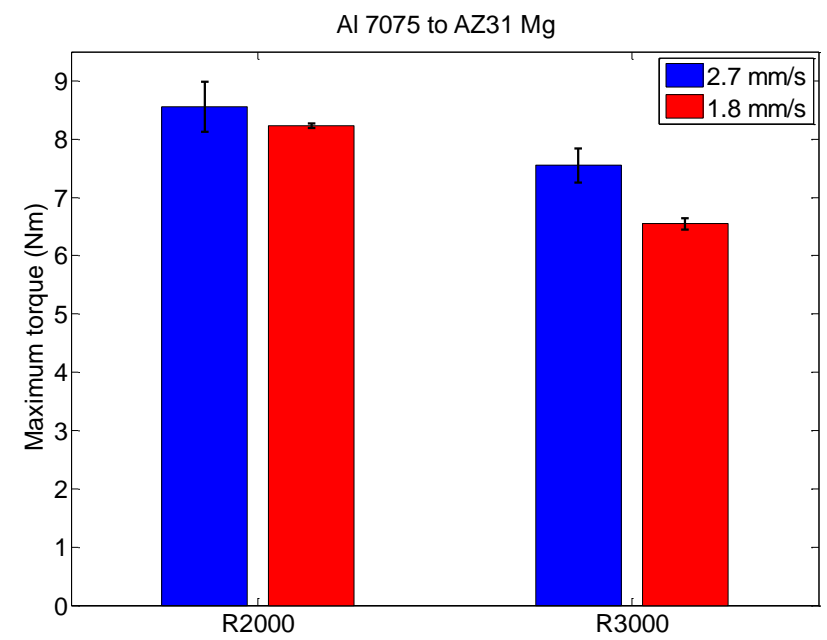

Fig. 6 Comparison of the peak torque under different process parameters 


\subsection{Macroscopic view of joint cross section}

Fig. 7 compares the joint cross sections obtained from different riveting conditions. Large scale weld deficiencies, including gaps and cracks were barely observable at the boundary between rivet leg and workpiece. Compared with the results of Li et al. (2013), where gap defects occurred at the outside boundary of rivet leg, improvements in this study is probably attributed to the instantaneous stop motion of the spindle. Based on the in-situ spindle speed measurement result, the stop time is less than 0.3s. It can be anticipated that as the spindle starts to retract from workpiece, redundant rotation of the rivet will generate instabilities, which are left as weld defects on the joint section. On the other hand, under the condition of $3000 \mathrm{rpm}$ rotating speed in this study, piles of aluminum scraps were observed beneath the center bottom surface of rivet head. One of the possible explanations is as the followings: When the tail of rivet starts to scratch the aluminum surface, certain amount of aluminum chips can be formed in condition of high rotating speed. As the rivet is punched further down, these scraps will likely be trapped inside the rivet tubular leg, which are then left as the features shown in Fig. 7 (c) and (d). Consistent with the results from Li et al. (2013), it can be observed that a higher rotating speed or slower plunge speed leads to smaller interlock distance of rivet leg. This can be considered together with the results of axial force measurement. With the same die geometry, smaller axial force indicates the force component perpendicular to the surface of die center is also lower, which accordingly provides insufficient force for pushing the rivet leg further outward. In other words, frictional heating helps soften aluminum and magnesium sheets, which facilitates the penetration of rivet and avoids cracks generation. However, the rivet leg spreading is also reduced due to the smaller force. In order to achieve better interlock properties, die geometry needs to be further improved or a force controlled F-SPR process can be employed.
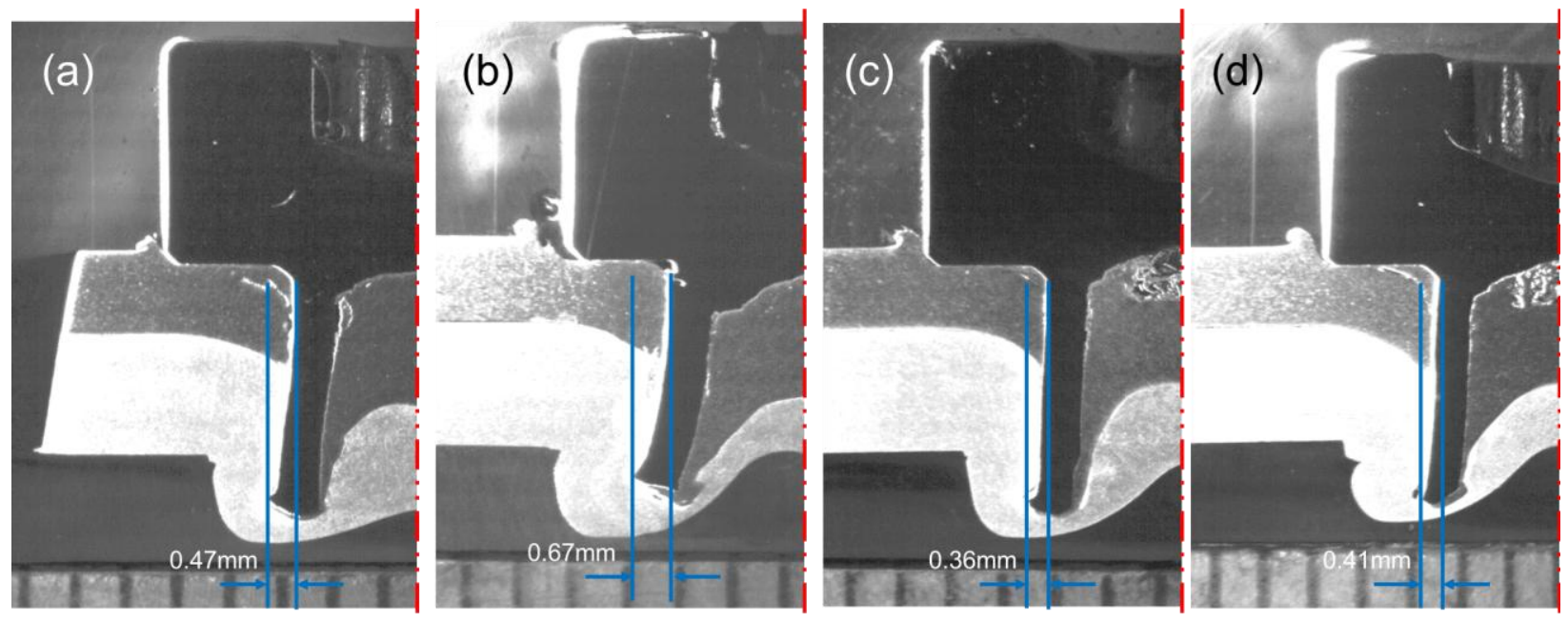

Fig. 7 Macroscopic view of joint cross section under different riveting conditions: (a) $2000 \mathrm{rpm} 1.8 \mathrm{~mm} / \mathrm{s}$; (b) $2000 \mathrm{rpm} 2.7 \mathrm{~mm} / \mathrm{s}$; (c) $3000 \mathrm{rpm} 1.8 \mathrm{~mm} / \mathrm{s}$; (d) $3000 \mathrm{rpm} 2.7 \mathrm{~mm} / \mathrm{s}$

\subsection{Microstructure analysis of joint interface}


Microstructures of the material interface at different locations of the joint are shown in Fig. 8 and the joint is obtained from rotating speed of $3000 \mathrm{rpm}$ and plunge speed of $2.7 \mathrm{~mm} / \mathrm{s}$. It can be observed that the cracks between the rivet leg and sheets reported in the works of Li et al. (2013) were basically indistinguishable even under a much higher magnification. Position 1 shows the interface between rivet head and top aluminum sheet, where discontinuous steel and aluminum chunks were distributed irregularly. Position 2 shows the junction where aluminum sheet, magnesium sheet and steel rivet appeared together at the outside boundary of rivet leg. Similar to the structure of Al-Fe interface in position 1, the Al-Mg interface were filled with chippings of aluminum and magnesium. Regarding the interaction between aluminum and rivet, a unique feature is that instead of simply penetrating through the top sheet, the rivet carries certain amount of aluminum together with it to flow downward while being plunged in. The possible existence of aluminum between rivet outside boundary and magnesium can also be observed at position 3, which is located at a further lower position in magnesium sheet. In order to verify the chemical composition of this strip, the position 3 has been zoomed in and a line scan EDS analysis was performed. Results are shown in Fig. 9 and a transition from iron into aluminum can be observed in the left region. On the right side, distribution of $\mathrm{Al}$ atoms gradually diminishes and $\mathrm{Mg}$ concentration starts to increase. There is a small gap of around 3um at the Al-Mg interface from the SEM view, where the corresponding concentrations of all three elements are trivial in the EDS analysis results. The formation of this gap is possibly due to the different thermal expansion coefficients of steel and magnesium. During cooling after the weld, magnesium contracts more compared with steel. Since the aluminum on the outside boundary of the rivet leg is flowing downward together with steel, the bonding strength between aluminum and steel is relatively higher than that between aluminum and magnesium. A small gap is accordingly generated at the Al-Mg interface.
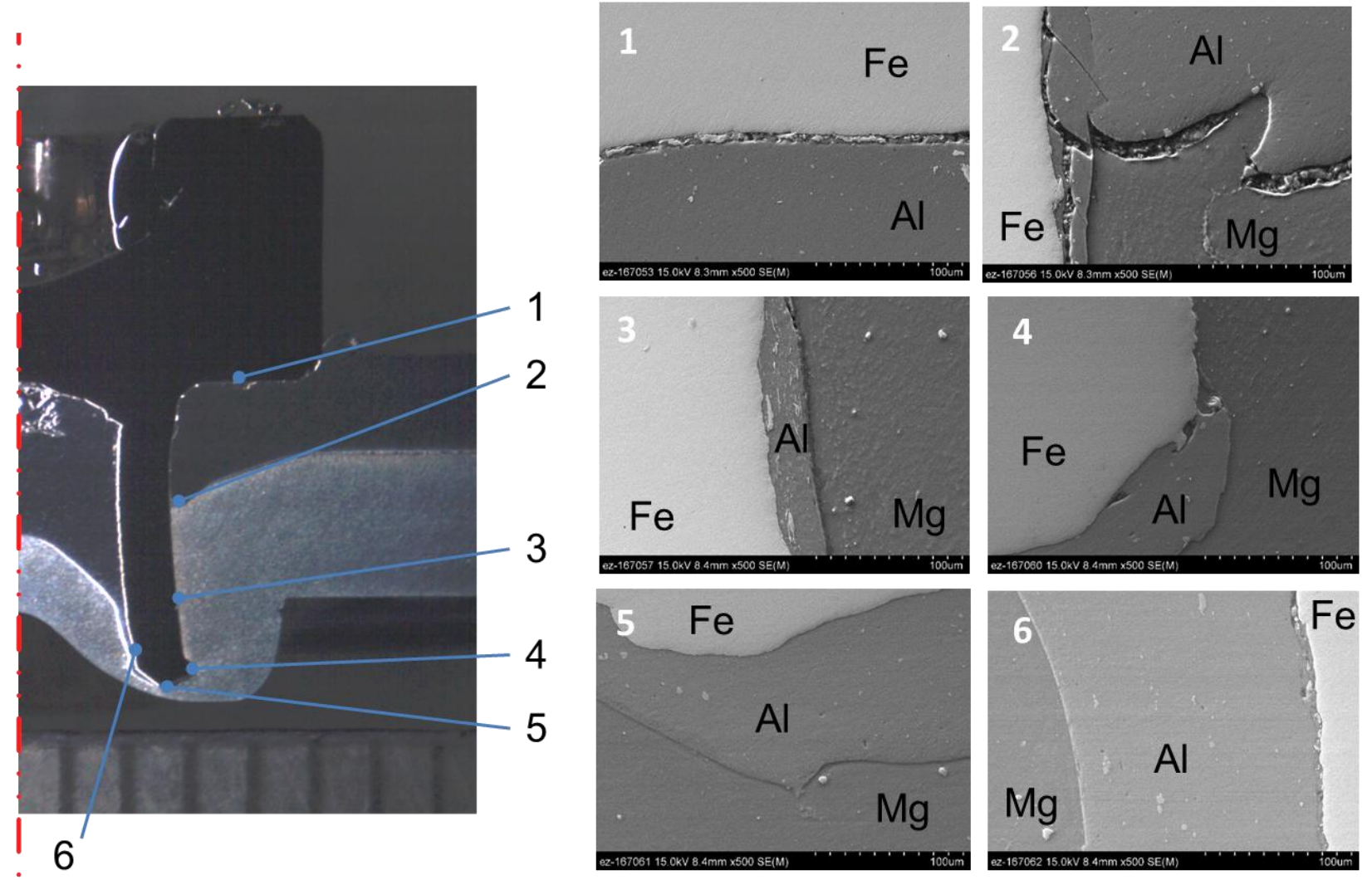
Fig. 8 Microstructure of dissimilar material interface at different positions under process condition of $3000 \mathrm{rpm}$ and $2.7 \mathrm{~mm} / \mathrm{s}$
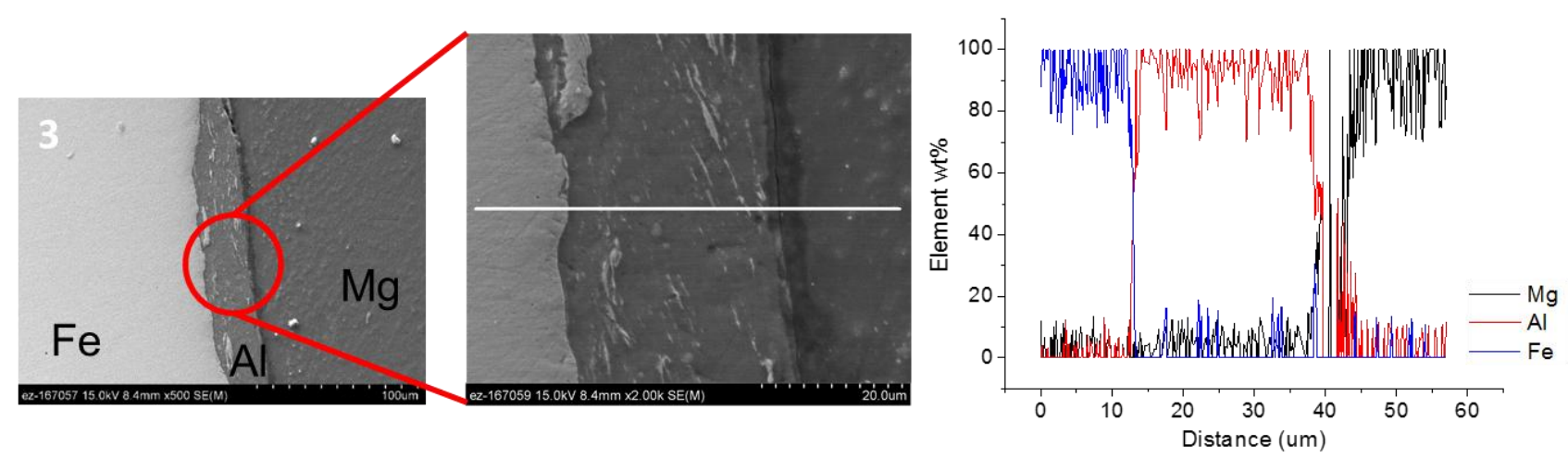

Fig. 9 EDS line scanning of elemental distribution at position 3 in Fig. 8

Position 4 and position 5 show the interface microstructure at the tail of the rivet. Position 4 is closer to the outside boundary of the rivet and position 5 is closer to the rivet inner surface. It can be observed that the aluminum at outside boundary is depleted near the rivet tip. On the other hand, aluminum inside of the rivet was stretched by the leg and flowed into the outside of the rivet tip. Cracks are hardly observable at the bottom of magnesium sheet due to its improved ductility from frictional heat.

Position 6 shows the material distribution at the inside lower boundary of the rivet leg. Aluminum can be observed to exist in between steel and magnesium. EDS line scanning was performed at the $\mathrm{Mg}-\mathrm{Al}$ interface to reveal possible intermetallics formation and the results are shown in Fig. 10. Two slopes can be observed in the transition zone between aluminum and magnesium. The small slope near magnesium side indicates possible formation of Al-Mg intermetallics and its thickness is around 5um. Near aluminum side, a higher slope of the elemental concentration curve suggests interdiffusion of the two atoms. For further verification, EDS mapping has also been performed at the same position for the entire area and the result is shown in Fig. 11. Gradual transition instead of a sharp interface between $\mathrm{Mg}$ and $\mathrm{Al}$ was observed, which exhibits interdiffusion of the two atoms and therefore bonding of the two materials.
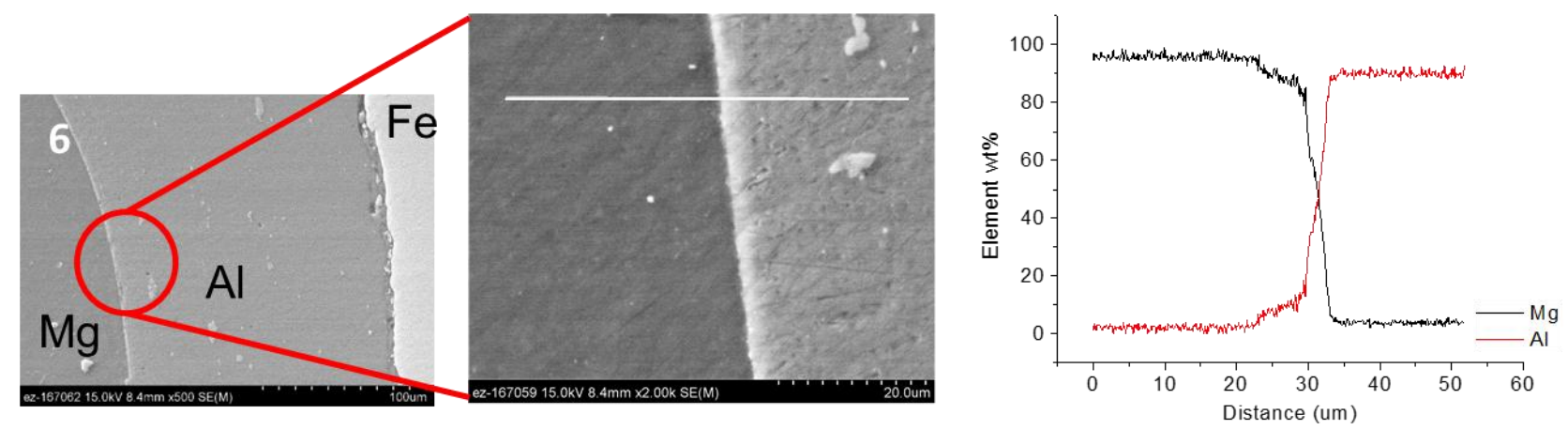

Fig. 10 EDS line scanning of elemental distribution at position 6 in Fig. 8 

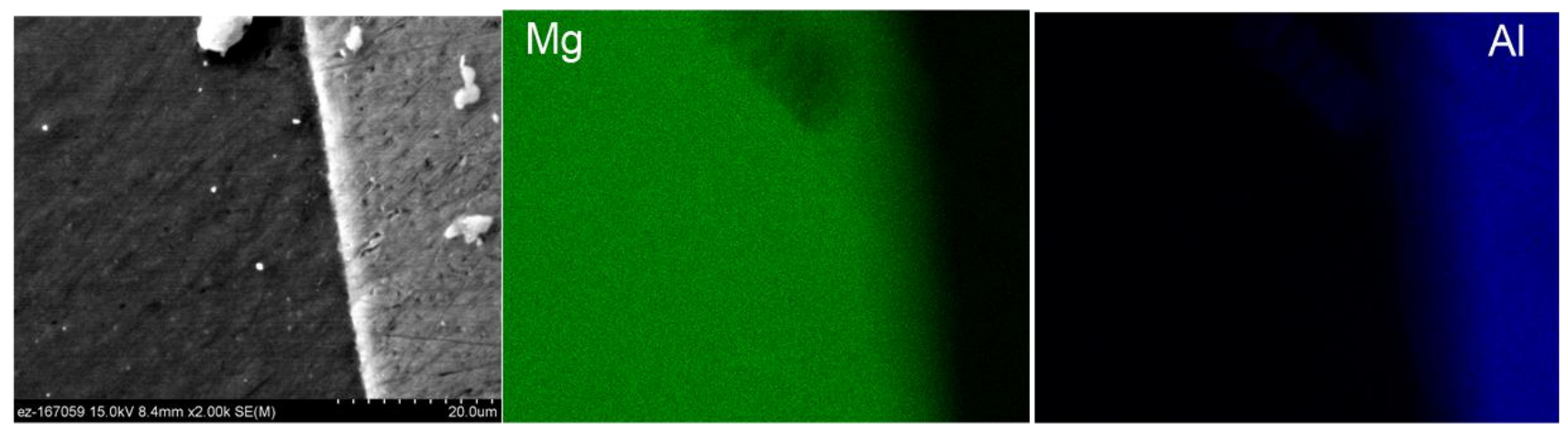

Fig. 11 Element distribution near the Mg-Al interface at position 6 in Fig. 8

Fig. 12 shows the material interface at different positions of the joint obtained from process condition of $2000 \mathrm{rpm}$ and $1.8 \mathrm{~mm} / \mathrm{s}$ plunge speed. Position 1 corresponds to the interface between root of rivet leg and aluminum. A small gap with thickness of less than 10um was observed, which is probably due to insufficient frictional heating from lower rotating speed. Another possible reason can be attributed to the curvature of this region, which results in a small force component normal to the surface. Effective bonding between the two workpiece can then hardly be achieved at this relatively lower temperature and pressure condition. Position 2 shows the Al-Mg interface slightly away from the rivet leg and similarly a thin gap with thickness of around 10um existed. Some amount of aluminum and magnesium fragments were distributed inside the gap. Position 3 shows the outside boundary of lower part of rivet leg in the magnesium sheet. Similar to the higher rotating speed condition, a possible layer of aluminum appeared in between the rivet and magnesium. However, the thickness is much smaller. Since less amount of frictional heat was generated under lower rotating speed, the plastic flowability of aluminum is accordingly lower. It is therefore more difficult for aluminum to flow downward together with the rivet leg. This aluminum layer became even thinner at further lower position 4 . In order to verify the composition of this layer and identify possible formation of intermetallics, position 3 and position 4 were further magnified for EDS line scanning analysis and the results are shown in Fig. 13 and Fig. 15 respectively. Position 5 and 6 show the material distribution at the tail of the rivet. Similar to the condition of higher rotating speed, the frictional force at the rivet interface can move the inside aluminum to the rivet tip. However, gaps were observed at the interface between aluminum and magnesium, which is probably due to the lower amount of frictional heating and consequent insufficient flowability of magnesium. Further temperature measurement should be performed to help directly quantify the difference of frictional heating under different process conditions. 

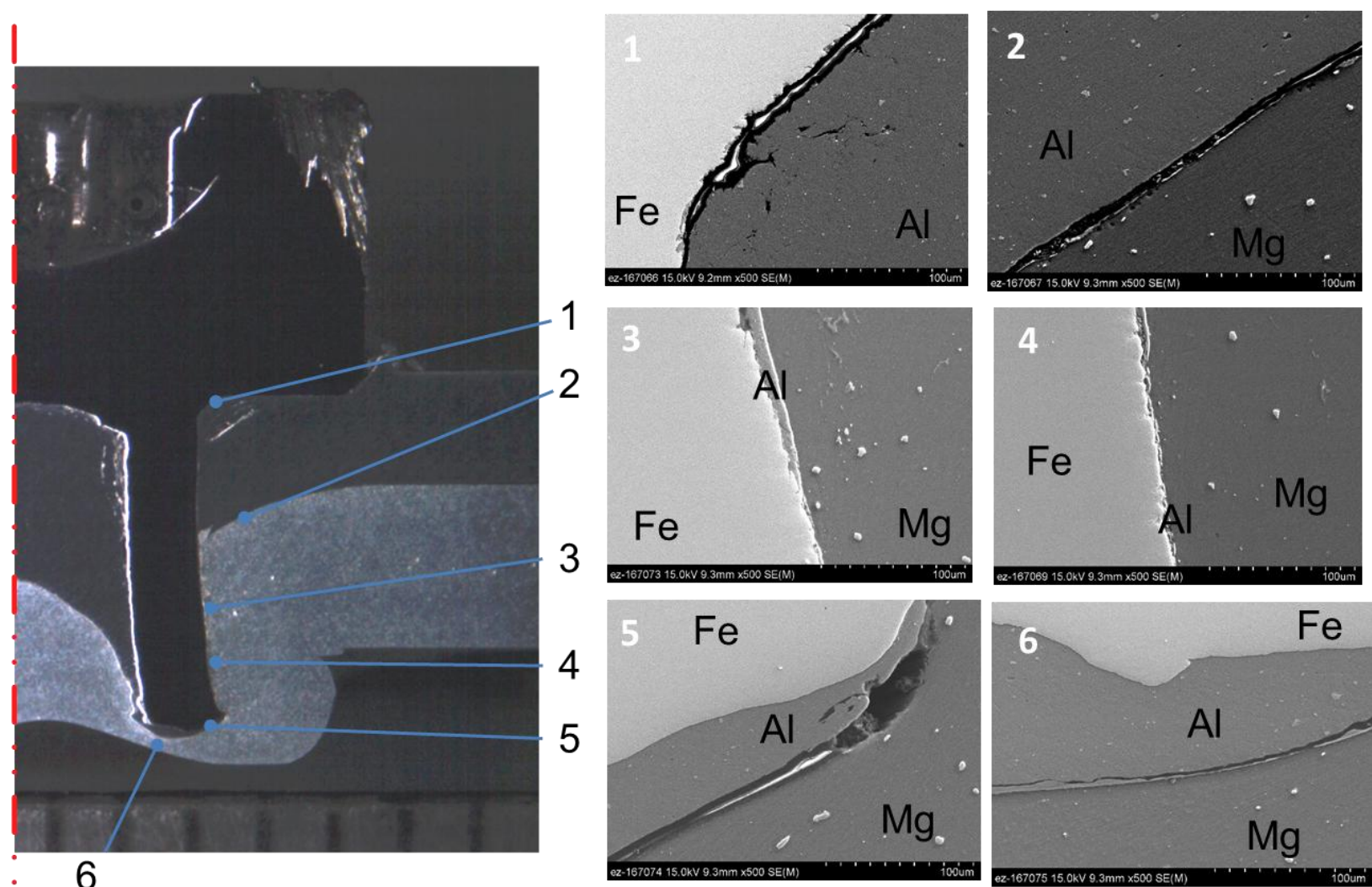

Fig. 12 Microstructure of dissimilar material interface at different positions under process condition of $2000 \mathrm{rpm}$ and $1.8 \mathrm{~mm} / \mathrm{s}$
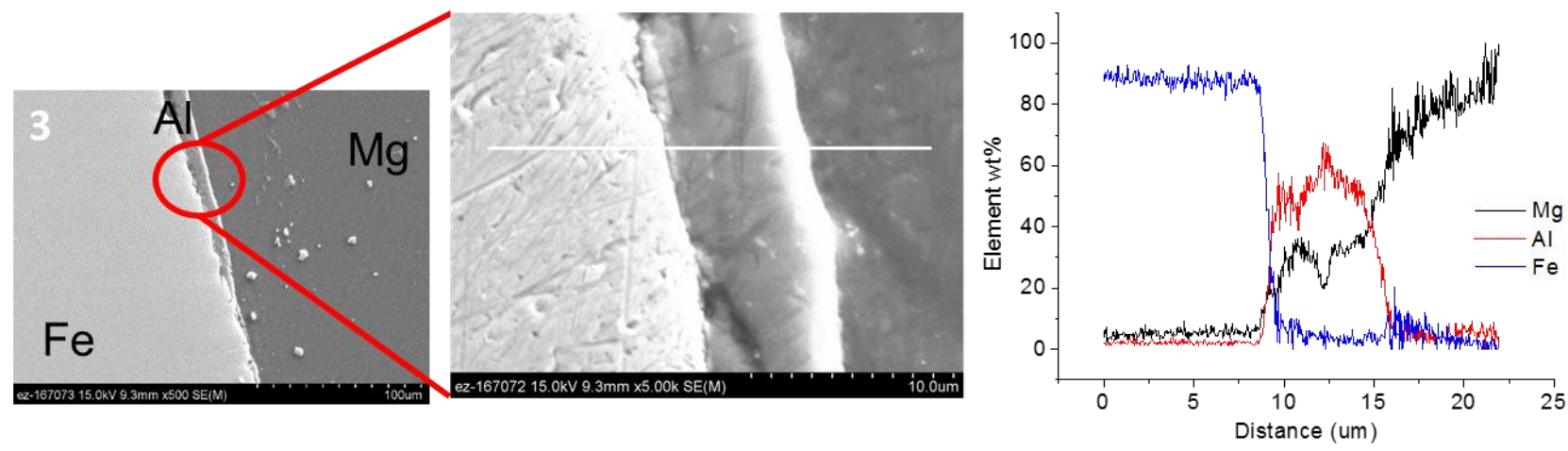

Fig. 13 EDS line scanning of elemental distribution at position 3 in Fig. 12 

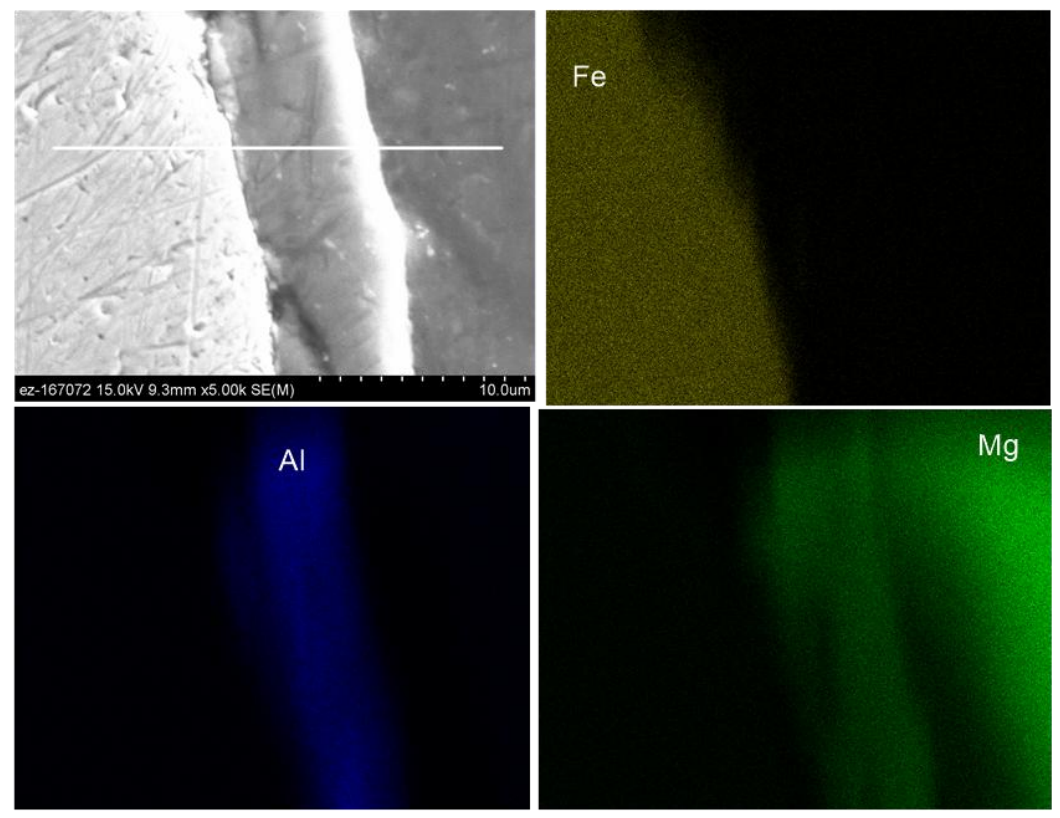

Fig. 14 Element distribution between the outside boundary of rivet leg and magnesium sheet

In Fig. 13, it can be observed that as the scanning point moved from steel to the middle layer, the concentration of iron atom dropped abruptly. On the other hand, concentrations of aluminum and magnesium started to increase at the same position and remained at a constant ratio for approximate $5 \mathrm{um}$ distance. This indicates the residual aluminum on the outside boundary of rivet leg would react with the magnesium sheet and form a thin layer of $\mathrm{Al}-\mathrm{Mg}$ intermetallic compound. Based on the relative weight ratio of the two elements and $\mathrm{Al}-\mathrm{Mg}$ phase diagram, the composition of this IMC layer can be $\mathrm{Mg}_{28} \mathrm{Al}_{45}$. EDS mapping was then performed on the entire area of Fig. 13 and the results are shown in Fig. 14. A relatively distinct interlayer existed between $\mathrm{Fe}$ and $\mathrm{Al}$ regions. An overlapping region of aluminum and magnesium atoms can also be observed, which further suggested formation of the Al-Mg intermetallics.

At the lower position 4, the aluminum concentration in the thin interlayer is relatively small from the EDS analysis results, as shown in Fig. 15. On the other hand, the concentration of Fe drops to a lower value and keeps at a constant ratio with that of $\mathrm{Mg}$. However, based on the $\mathrm{Fe}-\mathrm{Mg}$ phase diagram, $\mathrm{Fe}$ and $\mathrm{Mg}$ are basically insoluble and non-reactive to each other, which were also observed by Jana et al. (2010) when they did friction stir lap welding between steel and magnesium alloy. The constant ratio shown in this figure therefore suggests formation of some complex intermetallic compounds with additional elements involved, which also provides a possible bonding mechanism between steel and magnesium alloy. Further EDS mapping needs to be performed for verification in future works. 

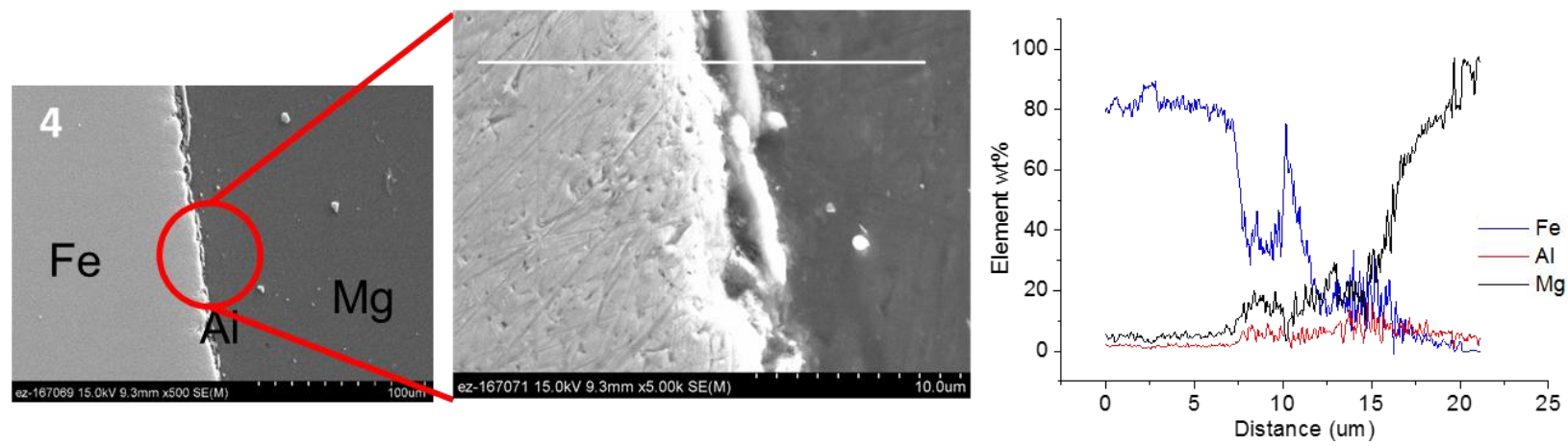

Fig. 15 EDS line scanning of elemental distribution at position 4 in Fig. 9

\subsection{Joint strength and failure mode analysis}

In order to evaluate the joint quality obtained from different welding conditions, tensile-shear tests were performed and the results are shown in Fig. 16. The peak tensile loads for joints obtained from all welding conditions are in the range of $4.2 \mathrm{kN}-5.6 \mathrm{kN}$, which are higher than F-SPR joints made with a machine without sudden stop motion, where the maximum value is $4 \mathrm{kN}$, or traditional SPR joints where the maximum is $2 \mathrm{kN}$ as reported by Li et al. (2013). According to Mori et al. (2006), equivalent strength for rivet joint can be determined through dividing the maximum tensile load by the tubular cross-sectional area of rivet leg. It can then be calculated that for the smallest tensile load value of $4.2 \mathrm{kN}$, the joint strength is around $190 \mathrm{MPa}$ based on the $5.3 \mathrm{~mm}$ outside diameter of rivet leg shown in Figure 1. This is higher than the yield strength of magnesium. For the four investigated riveting conditions, the obtained joints had similar maximum tensile loads. A higher plunge speed yielded slightly higher joint strength, which can be related to the larger interlock of rivet leg. According to Han and Chrysanthou (2008), a higher interlocking distance, contact pressure and contact frictional coefficient can enhance SPR joint quality under static shear loading condition. 


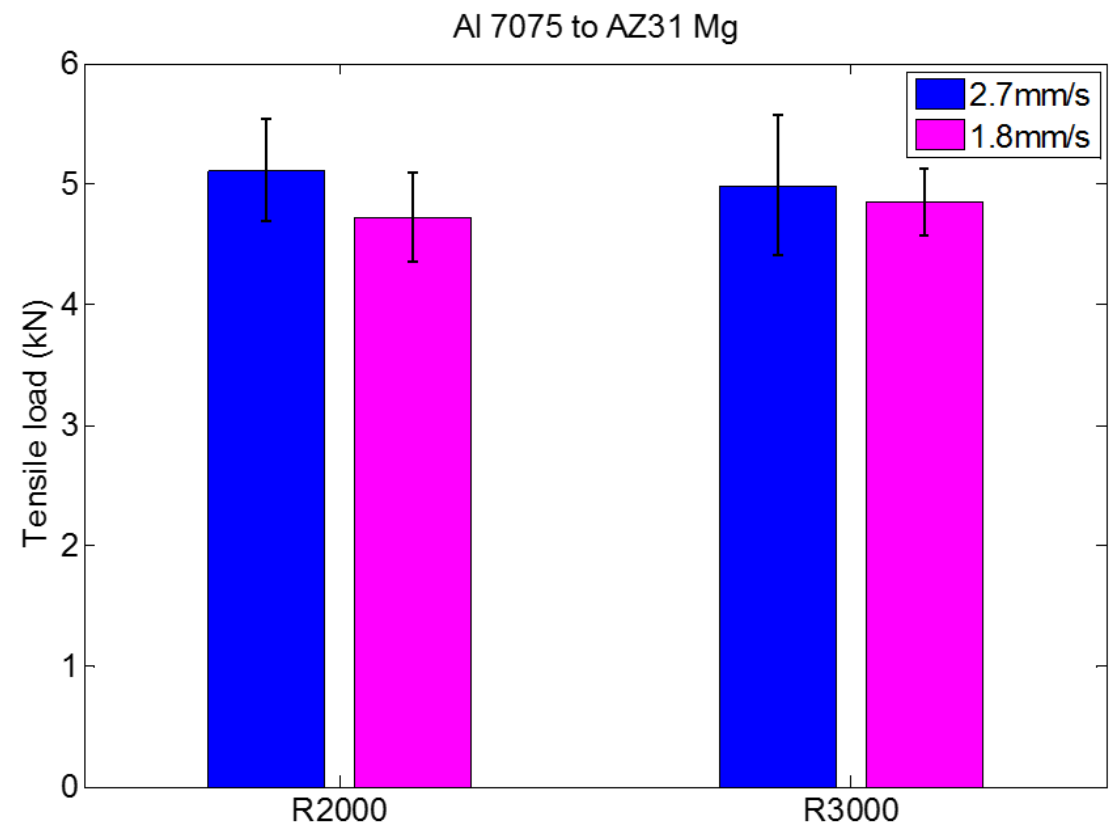

Fig. 16 Peak load during tensile-shear tests for joints obtained from different welding conditions

Fig. 17 presents the three failure modes that were identified during the tensile tests. Certain fraction of the tensile specimens failed by a combination of rivet pull-out and tearing of the bottom magnesium sheet, as shown in Fig. 17 (a-1) and Fig. 17 (a-2). The corresponding welding condition is rotating speed of 2000 $\mathrm{rpm}$ and plunge speed of $2.7 \mathrm{~mm} / \mathrm{s}$. It can be noticed that among the involved three materials, i.e. steel, AA7075 and magnesium alloy AZ31B, Mg alloy has the lowest strength. Besides, the thickness of remaining $\mathrm{Mg}$ near the buttonhole is small. Accordingly, cracks are likely to be initiated around the periphery of this region. Another possible cause is the relatively small interlock distance of the rivet leg in bottom Mg sheet, as shown in Fig. 7.

The second failure mode is basically only related to the lowest strength of $\mathrm{Mg}$. It can be observed in Fig. 17 (b) that the entire $\mathrm{Mg}$ sheet was sheared through. The corresponding welding condition is rotating speed of $3000 \mathrm{rpm}$ and plunge speed of $2.7 \mathrm{~mm} / \mathrm{s}$.
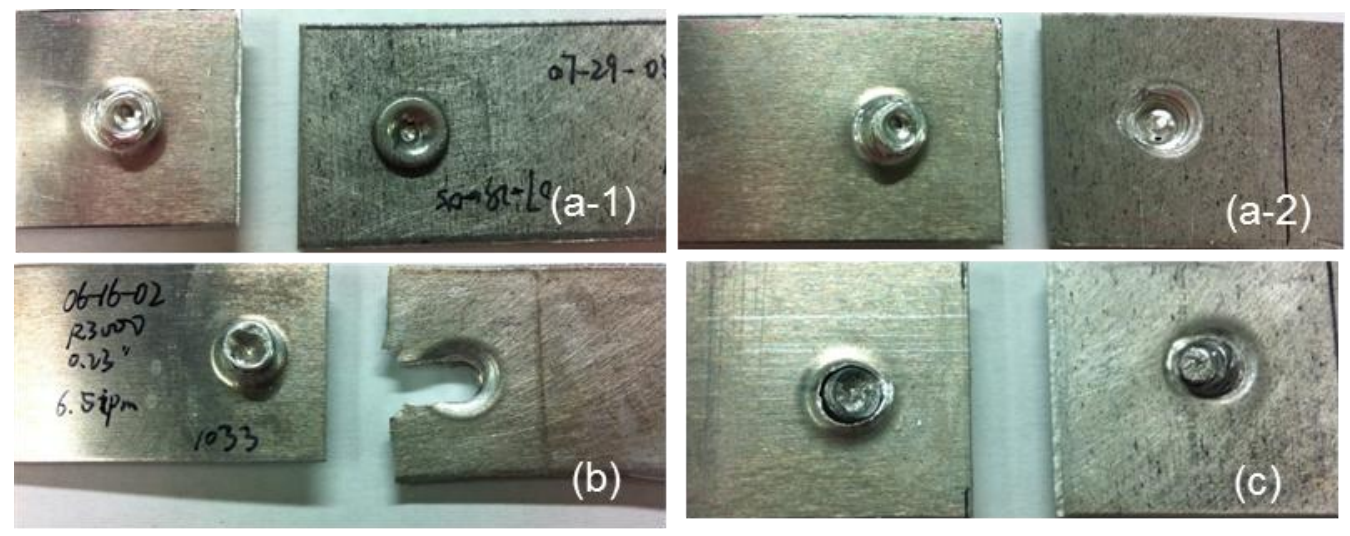
Fig. 17 Different failure modes identified during tensile tests: (a-1) Rivet pull-out: Bottom surface of the magnesium sheet is shown; (a-2) Rivet pull-out: Contact surface between riveted aluminum and magnesium sheet is shown; (b) Shear through of magnesium; (c) Rivet fracture is shown

The third failure mode is shown in Fig. 17 (c) and the welding condition for this specimen consists of rotating speed of $2000 \mathrm{rpm}$ and plunge speed of $1.8 \mathrm{~mm} / \mathrm{s}$. Fracture occurred on the rivet instead of on workpiece. In order to further reveal the underlying mechanism of this failure mode, microhardness distribution has been measured along rivet leg. Result is shown in Fig. 18 with the same welding condition as that in Fig. 17 (c). It can be observed that the hardness is much lower in the middle region of rivet leg. This can be explained as the followings: Due to frictional heating, the rivet material was either tempered or transformed to a softer phase than the original microstructure, which reduced the material strength in this region and initiated fracture during tensile-shear loading.

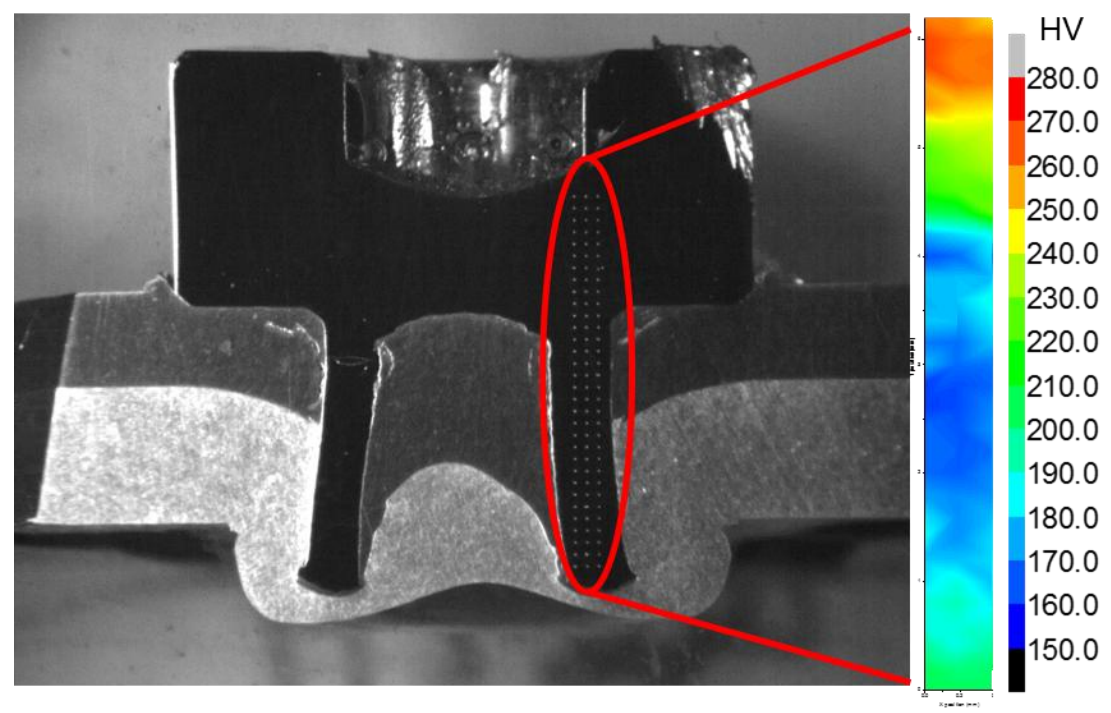

Fig. 18 Hardness distribution along the rivet leg (Welding condition: rotating speed of $2000 \mathrm{rpm}$ and plunge speed of $1.8 \mathrm{~mm} / \mathrm{s}$ )

Similar hardness distribution on the rivet leg was also observed under a higher rotating speed of $3000 \mathrm{rpm}$ and faster plunge speed of $2.7 \mathrm{~mm} / \mathrm{s}$, as shown in Fig. 19. Besides, to compare the relative strength of the involved three materials, additional hardness has been measured for AA7075 and AZ31 Mg in both the base material region and the region near rivet leg. The average hardness values at these different locations are listed in Table 2. It can be noticed that for the region of rivet leg immersed in $\mathrm{Al}$ and $\mathrm{Mg}$ sheet, the rivet hardness is approximately the same as that of AA7075. During tensile tests, a higher stress distribution on the rivet can easily lead to its breakage as in the third failure mode. The hardness of AA7075-T6 near rivet leg is smaller than its base material strength. This can be related to the frictional heat, which resulted in over aging and precipitate coarsening since T6 is a peak aged condition. On the other hand, strength of AZ31 Mg near the rivet remains basically unchanged. Also, it can be observed the magnesium alloy has the lowest hardness among all the three materials. 
Table 2 Average hardness at different locations on the joint cross section

\begin{tabular}{lllll}
\hline Location & $\mathbf{1}$ & $\mathbf{2}$ & $\mathbf{3}$ & $\mathbf{4}$ \\
\hline Average hardness (HV) & 171 & 66.5 & 149 & 68.9 \\
\hline
\end{tabular}

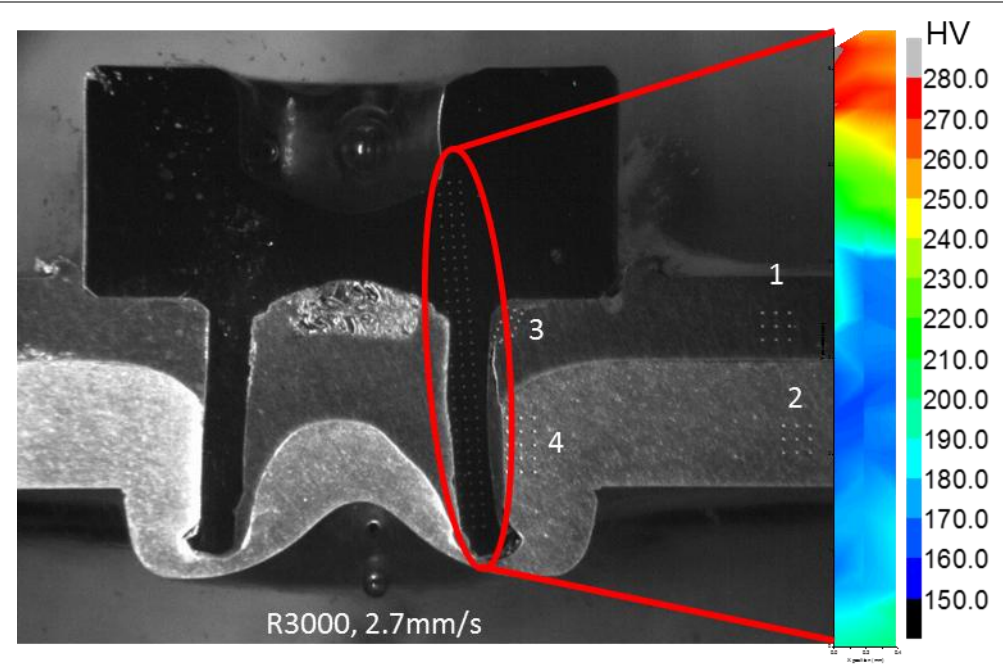

Fig. 19 Hardness distribution along the rivet leg (Welding condition: rotating speed of $3000 \mathrm{rpm}$ and plunge speed of $2.7 \mathrm{~mm} / \mathrm{s}$ )

In order to evaluate the joint strength from a different material configuration, welds were also performed with $\mathrm{Mg}$ sheet placed on top of $\mathrm{Al}$ sheet. The rivet plunge depth was kept the same at $5.84 \mathrm{~mm}$. Overview of the joint cross section is shown in Fig. 20 and it can be observed the rivet leg is well spread out. During tensile tests, rivet fracture occurred and the peak tensile load was $4.5 \mathrm{kN}$, which stays in the same range as the conditions where $\mathrm{Mg}$ is placed on the bottom.

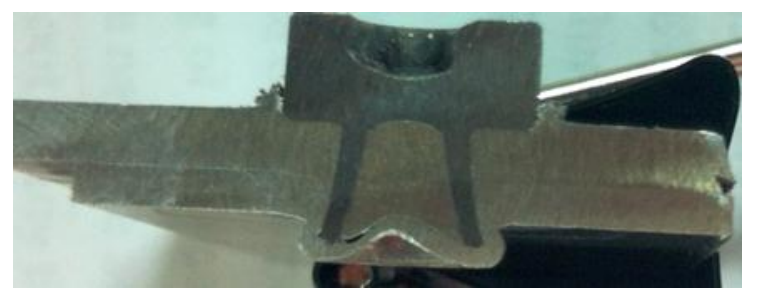

Fig. 20 Overview of the joint cross section where magnesium alloy AZ31B was placed on the top (Welding condition: rotating speed of $3000 \mathrm{rpm}$ and plunge speed of $2.7 \mathrm{~mm} / \mathrm{s}$ )

\section{Conclusions and future works}

Friction self-piercing riveting (F-SPR) has been applied for joining high strength aluminum alloy AA7075-T6 with AZ31 Mg alloy. The process was performed on a specially designed machine where the spindle can stop rotating abruptly. Effects of rotating and rivet punch speed on axial plunge force, torque, joint microstructure and quality have been investigated. Following conclusions can be drawn based on the study: 
(1) During F-SPR, there are two peaks on both force and torque curve. The maximum peak appears at the end of process when the rivet head reaches the top sheet. A small peak appears before the rivet pierced through the top aluminum sheet, which is due to the competing effect of frictional heating and material deformation resistance;

(2) Two of the major F-SPR parameters, rotation rate and punch speed, affect process axial force and torque. In general, high rotating speed and small punch speed can reduce axial force and torque, and the low axial force correspondingly resulted in a small interlock;

(3) The pierced through aluminum has been stretched downward into $\mathrm{Mg}$ sheet from the frictional force of rivet leg; Al-Mg intermetallics can form from the frictional heat and contact pressure; The rivet leg was surrounded by a thicker aluminum layer in conditions of larger rotating speed;

(4) F-SPR joint made with a machine with a sudden stop function are stronger than those obtained from a machine without such motion. Equivalent strength of the obtained joints were higher than the yield strength of AZ $31 \mathrm{Mg}$ alloy;

(5) Three failure modes were observed, i.e. pullout of rivet, shear through of $\mathrm{Mg}$ and fracture of rivet. Microhardness tests showed the local softening of rivet leg due to frictional heating.

In future works, etching can be performed on joint cross section for examination of possible dynamic recrystallization in both aluminum and magnesium. To directly evaluate the frictional heat effect, temperature will be measured during the process. To better understand material deformation behavior during the process, joining mechanisms and the observed force and torque curve, further experiments can be performed by stopping the process at different punch depths and examine the macrostructure of corresponding weld cross sections. Finite element analysis can also be performed, which can be verified by comparing with a higher resolution axial punching load, torque. This can further help provide insights into the process. Besides, better joint strength can be achieved with improved rivet material and die geometry.

\section{Acknowledgement}

This research was financially sponsored by the U.S. Department of Energy, Assistant Secretary for Energy Efficiency and Renewable Energy, Office of Vehicle Technologies, as part of the Lightweight Materials Program. Oak Ridge National Laboratory (ORNL) is managed by UT-Battelle, LLC for the U.S. Department of Energy under Contract DE-AC05-00OR22725. The authors would also like to acknowledge the supports of National Natural Science Foundation of China (Grant Nos. 51275300, 51322504, U1564204 and 51375308), Program for New Century Excellent Talents in University by Ministry of Education of China (NCET-12-0361), the Program of Introducing Talents of Discipline to Universities (Grant No. B06012) and the Research Project of State Key Laboratory of Mechanical System and Vibration MSVZD201411. 


\section{References}

Abe, Y., Kato, T., Mori, K., 2006. Joinability of aluminium alloy and mild steel sheets by self piercing rivet. J. Mater. Process. Technol. 177, 417-421.

Di Franco, G., Fratini, L., Pasta, A., Ruisi, A.F., 2010. On the self-piercing riveting of aluminium blanks and carbon fibre composite panels. Int J Mater Form 3, 1035-1038.

Durandet, Y., Deam, R., Beer, A., Song, W., Blacket, S., 2010. Laser assisted self-pierce riveting of AZ31 magnesium alloy strips. Mater. Des. 31, Supplement 1, S13-S16.

Gao, D., Ersoy, U., Stevenson, R., Wang, P.-C., 2009. A new one-sided joining process for aluminum alloys: Friction Stir Blind Riveting. J. Manuf. Sci. Eng. 131, 061002.

Han, L., Chrysanthou, A., 2008. Evaluation of quality and behaviour of self-piercing riveted aluminium to high strength low alloy sheets with different surface coatings. Mater. Des. 29, 458-468.

Haque, R., Beynon, J.H., Durandet, Y., 2012. Characterisation of force-displacement curve in self-pierce riveting. Sci. Technol. Weld. Joining 17, 476-488.

He, X., Pearson, I., Young, K., 2008. Self-pierce riveting for sheet materials: state of the art. J. Mater. Process. Technol. 199, 27-36.

Jäger, A., Lukáč, P., Gärtnerová, V., Bohlen, J., Kainer, K.U., 2004. Tensile properties of hot rolled AZ31 Mg alloy sheets at elevated temperatures. J. Alloys Compd. 378, 184-187.

Jana, S., Hovanski, Y., Grant, G.J., 2010. Friction Stir Lap Welding of Magnesium Alloy to Steel: A Preliminary Investigation. Metall. Mater. Trans. A 41, 3173-3182.

Li, Y., Wei, Z., Wang, Z., Li, Y., 2013. Friction Self-Piercing Riveting of Aluminum Alloy AA6061-T6 to Magnesium Alloy AZ31B. J. Manuf. Sci. Eng. 135, 061007.

Lim, Y.C., Squires, L., Pan, T.-Y., Miles, M., Song, G.-L., Wang, Y., Feng, Z., 2015. Study of mechanical joint strength of aluminum alloy 7075-T6 and dual phase steel 980 welded by friction bit joining and weld-bonding under corrosion medium. Mater. Des. 69, 37-43.

Liu, X., Lan, S., Ni, J., 2014. Analysis of process parameters effects on friction stir welding of dissimilar aluminum alloy to advanced high strength steel. Mater. Des. 59, 50-62.

Lou, M., Li, Y., Li, Y., Chen, G., 2013. Behavior and Quality Evaluation of Electroplastic Self-Piercing Riveting of Aluminum Alloy and Advanced High Strength Steel. J. Manuf. Sci. Eng. 135, 011005011005.

Ma, Y., Li, Y., Hu, W., Lou, M., Lin, Z., 2016. Modeling of Friction Self-Piercing Riveting of Aluminum to Magnesium. J. Manuf. Sci. Eng. 138, 061007.

Ma, Y., Lou, M., Yang, Z., Li, Y., 2015. Effect of Rivet Hardness and Geometrical Features on Friction Self-Piercing Riveted Joint Quality. J. Manuf. Sci. Eng.

Mandel, M., Krüger, L., 2012. Electrochemical corrosion studies and pitting corrosion sensitivity of a self-pierce rivet joint of carbon fibre reinforced polymer (CFRP) - laminate and EN AW-6060-T6.

Materialwiss. Werkstofftech. 43, 302-309.

Miles, M., Feng, Z., Kohkonen, K., Weickum, B., Steel, R., Lev, L., 2010. Spot joining of AA 5754 and high strength steel sheets by consumable bit. Science and Technology of Welding \& Joining 15, 325-330. Min, J., Li, J., Li, Y., Carlson, B.E., Lin, J., Wang, W.-M., 2015. Friction stir blind riveting for aluminum alloy sheets. J. Mater. Process. Technol. 215, 20-29.

Mori, K., Abe, Y., Kato, T., 2014. Self-pierce riveting of multiple steel and aluminium alloy sheets. J. Mater. Process. Technol. 214, 2002-2008.

Mori, K., Kato, T., Abe, Y., Ravshanbek, Y., 2006. Plastic Joining of Ultra High Strength Steel and Aluminium Alloy Sheets by Self Piercing Rivet. CIRP Annals - Manufacturing Technology 55, 283-286. Park, K., 2009. Development and Analysis of Ultrasonic Assisted Friction Stir Welding Process. University of Michigan, $\mathrm{PhD}$ dissertation.

Porcaro, R., Hanssen, A., Langseth, M., Aalberg, A., 2006. Self-piercing riveting process: An experimental and numerical investigation. J. Mater. Process. Technol. 171, 10-20. 
Skovron, J., Mears, L., Ulutan, D., Detwiler, D., Paolini, D., Baeumler, B., Claus, L., 2014.

Characterization of Flow Drill Screwdriving Process Parameters on Joint Quality. SAE International Journal of Materials and Manufacturing 8, 35-44.

Skovron, J.D., Prasad, R.R., Ulutan, D., Mears, L., Detwiler, D., Paolini, D., Baeumler, B., Claus, L., 2015. Effect of Thermal Assistance on the Joint Quality of Al6063-T5A During Flow Drill Screwdriving. J. Manuf. Sci. Eng. 137, 051019.

Somasekharan, A., Murr, L., 2004. Microstructures in friction-stir welded dissimilar magnesium alloys and magnesium alloys to 6061-T6 aluminum alloy. Mater. Charact. 52, 49-64.

Squires, L., Lim, Y., Miles, M., Feng, Z., 2015. Mechanical properties of dissimilar metal joints composed of DP 980 steel and AA 7075-T6. Sci. Technol. Weld. Joining 20, 242-248.

Troitskii, O., 1969. Electromechanical effect in metals. ZhETF Pis ma Redaktsiiu 10, 18.

Wang, J.W., Liu, Z.X., Shang, Y., Liu, A.L., Wang, M.X., Sun, R.N., Wang, P.-C., 2011. Self-Piercing

Riveting of Wrought Magnesium AZ31 Sheets. J. Manuf. Sci. Eng. 133, 031009-031009. 
Table 1 Mechanical properties and sheet thickness of AA7075-T6 Al alloy and AZ31B Mg alloy

\begin{tabular}{lllll} 
Material & Yield strength & Uniaxial tensile strength & Elongation & Thickness \\
\hline AA7075-T6 [24] & $503 \mathrm{MPa}$ & $572 \mathrm{MPa}$ & $11 \%$ & $2.3 \mathrm{~mm}$ \\
\hline AZ31B [14] & $169 \mathrm{MPa}$ & $297 \mathrm{MPa}$ & $8 \%$ & $1.6 \mathrm{~mm}$ \\
\hline
\end{tabular}


Table 2 Average hardness at different locations on the joint cross section

\begin{tabular}{lllll} 
Location & $\mathbf{1}$ & $\mathbf{2}$ & $\mathbf{3}$ & $\mathbf{4}$ \\
\hline Average hardness (HV) & 171 & 66.5 & 149 & 68.9
\end{tabular}

